\title{
Comparison of Intakes of US Chinese Women Based on Food Frequency and 24-Hour Recall Data
}

MARILYN TSENG, PhD; TERESITA HERNÁNDEZ, PhD

\begin{abstract}
The objective of this cross-sectional study was to compare dietary reports from a food frequency questionnaire (FFQ) for US Chinese women with 24-hour recall estimates. The subjects were 56 women recruited through organizations in Philadelphia's Chinese community. Spearman correlations were used to describe FFQ estimates of food servings per month and nutrient intake per day vs estimates from three 24-hour recalls over 1 month. On average, women reported at least weekly consumption of 28 of $96 \mathrm{FFQ}$ food items. The three most frequently consumed were rice (38 times/month), tea (29 times/ month), and dark green, leafy vegetables (18 times/ month). Comparing reported frequencies of the 28 foods to 24-hour recall estimates, the median Spearman correlation was 0.36. For nutrient estimates, correlations were high $(r>0.5)$ for dietary fiber and calcium; moderate $(r=0.25$ to 0.5$)$ for energy, saturated fat, cholesterol, carbohydrates, protein, folic acid, and iron; but poor $(r<0.25)$ for total fat, vitamin $\mathrm{C}$, vitamin $\mathrm{A}$, and carotene. These findings provide some assurance of the FFQ's adequacy for describing US Chinese women's intake of commonly consumed foods and selected nutrients. They also provide a basis for further improvements to, and evaluations of, the FFQ.
\end{abstract}

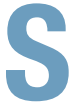

tudies describing diet in Chinese immigrants to the United States can offer insight into the role of diet in health transitions with migration but require a population-appropriate dietary assessment instrument. Twenty-four-hour recalls or records provide quantitative information but are costly and burdensome to obtain because of the multiple days required to characterize usual diet. Because food frequency questionnaires (FFQ) have the advantages of low cost and ease of administration, we

M. Tseng is an associate member of the Fox Chase Cancer Center Philadelphia, PA. T. Hernández is president of Health Technomics, Inc, Annandale, VA.

Address correspondence to: Marilyn Tseng, PhD, Fox Chase Cancer Center, 333 Cottman Ave, Philadelphia, developed an FFQ to describe dietary intake in less acculturated women of Chinese ethnicity in Philadelphia, PA. Here we compare it with 24-hour recalls in its ability to capture commonly consumed foods and major nutrient sources and to rank individuals based on their food and nutrient intake.

\section{METHODS}

\section{Questionnaire Development}

The FFQ food list and referent portion sizes were based on previous instruments for Asian Americans (1,2). Revisions to previous food lists were based on feedback from two focus groups, one conducted in Mandarin and the other in Cantonese. Each focus group included eight to 10 women of Chinese ethnicity, aged 40 to 75 years, and recruited through churches in Philadelphia's Chinatown. Focus groups were led by the principal investigator and by a moderator fluent in Chinese and trained in the research study and focus group objectives. Participants were asked about commonly eaten foods not on previous lists, unimportant foods that could be omitted, and specific foods that would be included within a food group.

In the resulting $\mathrm{FFQ}$, respondents estimated their consumption frequency over the previous year for 96 foods. While portion-size options were offered, frequency questions were open-ended. Other aspects of the FFQ's format were based on and used with the permission of Block Dietary Data Systems (Berkeley, CA). Also, digital photographs illustrated spoon, cup, and bowl volumes, and referent portion sizes for foods, such as $3 \mathrm{oz}$ of meat or a slice of pizza. The FFQ food list and a sample page with visual aids can be accessed at www.fccc.edu/research/ labs/tseng/TsengACS01.html.

A corresponding nutrient database was compiled by Health Technomics, Inc (Annandale, VA) (3) and was derived from the US Department of Agriculture's (USDA) database used in the 1994-96 Continuing Survey of Food Intakes by Individuals (4) and Release 12 of the USDA Nutrient Database for Standard Reference (5), both updated using USDA provisional carotenoid tables (6). For grouped foods, we used the mean nutrient value for the most common foods in each group as reported in focus groups. The database also included values for grams of food per unit (eg, cup). Nutrient intake was estimated as the product of each food's consumption frequency and amount (in specified units) as reported on the FFQ, number of grams per food unit, and nutrient content per $100 \mathrm{~g}$, summed over all food items. 


\begin{tabular}{|lc|}
\hline \multicolumn{2}{|l|}{ Table 1. Sociodemographic characteristics of US Chinese women } \\
participating in a study comparing dietary reports from a food \\
frequency questionnaire with 24-hour recall estimates (N=56) \\
\hline Characteristics \\
\hline Mean age, y (range) & $54(34-88)$ \\
& $\mathbf{n}(\%)$ \\
Married or living as married & $45(80)$ \\
Level of education & \\
< High school graduate & $18(32)$ \\
High school graduate and some college & $12(21)$ \\
College graduate & $17(30)$ \\
Graduate degree & $9(16)$ \\
Language spoken mostly & $32(57)$ \\
Chinese & $19(34)$ \\
Both Chinese and English equally & $5(9)$ \\
English & \\
Place of birth & $42(75)$ \\
China & $8(14)$ \\
Hong Kong & $2(4)$ \\
Taiwan & $4(8)$ \\
Other ${ }^{a}$ & \\
\hline${ }^{a} 0 t h e r$ places were Singapore; Vietnam; Panama; and Philadelphia, PA. \\
\hline
\end{tabular}

\section{Data Collection}

Participants were recruited through organizations and community contacts in the Philadelphia Chinatown community. Although women $\geq 40$ years old were targeted, the age criterion was relaxed to facilitate recruitment. Women were excluded if they had no telephone, were pregnant, or had a recent illness necessitating major dietary changes.

FFQ interviews were conducted in person or over the telephone by an interviewer fluent in Mandarin or Cantonese. Except for some mixed dishes, such as fried rice and jook, participants were asked about their consumption of single food items (eg, broccoli), whether occurring in mixed dishes (eg, beef with broccoli) or as single foods (eg, stir-fried broccoli as a dish). Three unannounced 24-hour recall interviews were administered over the telephone over the following month, targeting 2 weekdays and 1 weekend day. To facilitate portion-size estimation, participants received visual aids illustrating spoon and cup amounts, lengths, and diameters; they were also advised to consider the amount of food purchased, number with whom they shared a dish, proportion on the serving plate that they consumed, and proportion of mixed dishes made up of the ingredient of interest. Interviewers followed a standardized protocol for interviewing and entering responses into the Food Intake Analysis System (FIAS v. 3.99, July 2000; University of Texas, Houston), whose nutrient database is derived from the USDA 1994-96 Continuing Survey of Food Intakes by Individuals (4). Foods not in the database were added using Health Technomics, Inc database values (3). Mixed dishes were entered by using or modifying recipes from the FIAS and Health Technomics, Inc databases $(3,4)$.

\section{Data Analysis}

Spearman correlations were used to assess the FFQ's ability to rank individuals based on their food and nutri-
Table 2. Foods consumed on average at least once per month based on 24-hour recall data of 56 US Chinese women

\begin{tabular}{|c|c|c|c|}
\hline \multirow[b]{2}{*}{$F_{F Q}{ }^{a}$ food item } & \multicolumn{2}{|c|}{$\begin{array}{c}\text { Mean } \\
\text { Frequency of } \\
\text { Intake Per } \\
\text { Month }\end{array}$} & \multirow[b]{2}{*}{$\begin{array}{l}\text { Spearman } \\
\text { correlations }\end{array}$} \\
\hline & $\begin{array}{l}\text { 24-hour } \\
\text { recalls }\end{array}$ & FFQ & \\
\hline Rice & 31.8 & 37.9 & 0.65 \\
\hline Pork & 22.9 & 16.1 & 0.33 \\
\hline Broth or soup & 20.9 & 8.2 & 0.27 \\
\hline Dark green, leafy vegetables & 19.3 & 18.1 & 0.18 \\
\hline Chicken or turkey & 16.6 & 11.8 & 0.30 \\
\hline Oolong or black tea & 16.4 & 28.9 & 0.63 \\
\hline Low-fat or skim milk & 14.1 & 15.8 & 0.84 \\
\hline White bread & 13.4 & 7.1 & 0.38 \\
\hline \multicolumn{4}{|l|}{ Other seafood, such as } \\
\hline shrimp or crab & 11.8 & 2.9 & 0.25 \\
\hline Eggs & 11.6 & 9.3 & 0.44 \\
\hline Oranges or tangerines & 11.4 & 17.4 & 0.44 \\
\hline Apples or pears & 10.4 & 16.4 & 0.42 \\
\hline Coffee & 9.5 & 12.8 & 0.92 \\
\hline Tofu & 8.9 & 5.9 & 0.38 \\
\hline Eggplant or squashes & 8.2 & 4.8 & 0.21 \\
\hline Bananas & 7.0 & 13.1 & 0.56 \\
\hline Beef & 7.0 & 5.7 & 0.41 \\
\hline Cake, pies, or Danish pastry & 6.3 & 1.1 & 0.02 \\
\hline \multicolumn{4}{|l|}{ Chinese-style noodles or } \\
\hline rice noodles & 6.1 & 2.0 & 0.18 \\
\hline Steamed fish & 5.9 & 6.8 & 0.52 \\
\hline \multicolumn{4}{|l|}{$100 \%$ orange or grapefruit } \\
\hline juice & 5.2 & 9.5 & 0.58 \\
\hline Carrots & 4.8 & 4.9 & 0.18 \\
\hline Beans or peas & 4.5 & 3.9 & -0.03 \\
\hline Salty snacks & 4.5 & 2.6 & 0.25 \\
\hline Whole milk & 4.5 & 6.5 & 0.47 \\
\hline Soda & 4.5 & 3.4 & 0.26 \\
\hline Bean sprouts & 4.3 & 2.4 & 0.17 \\
\hline \multicolumn{4}{|l|}{ Peanuts or other nuts or } \\
\hline seeds & 4.1 & 4.7 & 0.17 \\
\hline Median correlation & - & - & 0.36 \\
\hline
\end{tabular}

ent intake as compared with three 24-hour recalls per subject. Nutrient distributions were log-transformed as necessary. Correlations were examined for absolute intake and energy-adjusted using the residual method (7).

\section{RESULTS}

Characteristics of the 56 women recruited into the study are given in Table 1 . Mean age was 54 years, and most were born in mainland China (75\%) or Hong Kong (14\%). Over half (57\%) spoke primarily Chinese and only 9\% spoke primarily English. We obtained 24-hour recalls for 2 weekdays and 1 weekend day for 35 women; data on 3 weekdays were available for 11 women, and the remaining 10 women provided data for no more than 1 weekday of the 3 interview days. 
Table 3. Percent of nutrient intake captured by food frequency questionnaire (FFQ) items, and correlations between 24-hour recall- and FFQ-based estimates for 56 US Chinese women

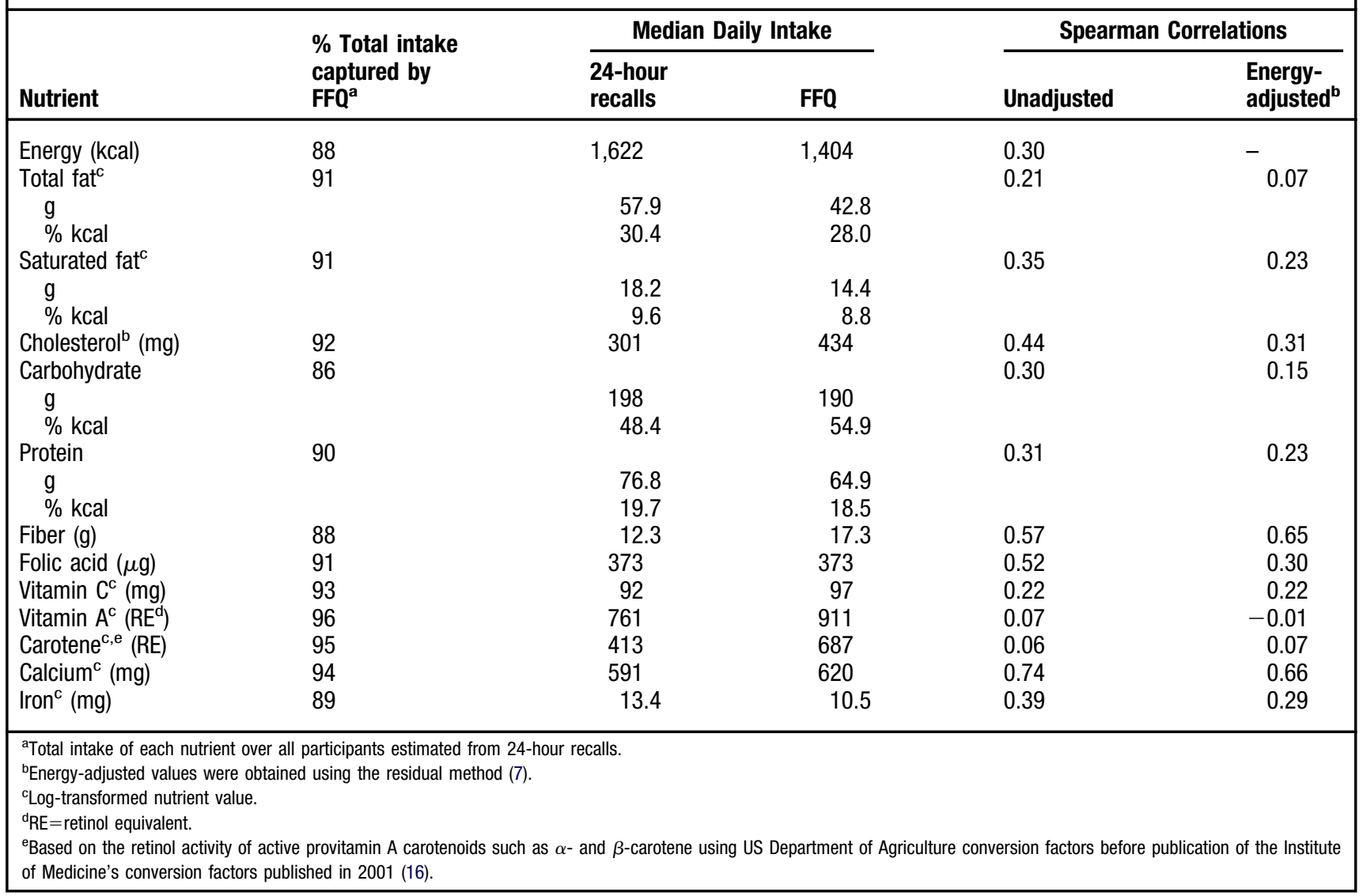

The FFQ food list included 68 of 98 foods eaten at least once a month on average based on 24-hour recalls, and 28 of 30 foods eaten at least once a week. The most frequently consumed foods reported in 24-hour recalls were rice, pork, and soups or broths; in FFQs they were rice, tea, and dark green, leafy vegetables (Table 2). Foods reported in 24-hour recalls but not suggested for inclusion by focus groups included some vegetables consumed in mixed dishes (eg, mushrooms, celery, bell peppers), bread items (steamed buns, bagels, fried dough sticks), other meats (eg, stewed fish, fish cakes), and dessert soups.

For the 28 foods consumed at least weekly, the median Spearman correlation between FFQ and 24-hour recall consumption frequencies was 0.36 (Table 2). Foods with high correlations included rice, beverages (eg, tea, coffee, orange juice), bananas, and steamed fish. Moderately correlated foods included meats (eg, pork, beef), bread, several fruits (oranges/tangerines, apples/pears), and tofu. Foods with low correlations included several vegetables (eg, green, leafy vegetables, carrots, beans/peas, bean sprouts), and cakes/pastries.

The food list captured $>85 \%$ of intake of the nutrients of interest (Table 3). Spearman correlations were between 0.25 and 0.50 for most nutrients (energy, saturated fat, cholesterol, carbohydrates, protein, folic acid, iron); higher $(r>0.5)$ for dietary fiber and calcium; but poor $(r<0.25)$ for total fat, vitamin C, vitamin A, and carotene. Energy adjustment did not improve correlations. Food and nutrient correlations were not meaningfully different in analyses including only 35 women who completed 2 weekdays and 1 weekend day, or only 30 women who reported a "usual" level of intake on all 3 recall days.

\section{DISCUSSION}

In a new FFQ for US Chinese women, the food list, adapted from previous questionnaires, captured most of the commonly consumed foods reported in 24-hour recalls and $>85 \%$ of intake of the nutrients of interest. Correlations between FFQ and 24-hour recalls were related to each food's average frequency of consumption $(r=0.41)$, probably because more commonly consumed foods are recalled more accurately or have higher between-person variability (8). Notably, they were also less likely to occur in mixed dishes, although the effect of mixed dishes on frequency estimation could not be formally evaluated.

Although the relatively small sample size is a limitation of the study, participants' FFQs and their detailed 24-hour recall responses provide valuable information on food and nutrient intake among US Chinese women, as well as on the FFQ's strengths and weaknesses. The use 
of different nutrient databases is another limitation. Previous work, however, suggests that using different database values has relatively little effect on ranking or agreement between FFQ and a referent (9-11).

Comparing FFQ estimates with only 3 days of 24 -hour recalls may understate the FFQ's performance. Three 24-hour recalls over 1 month might not reflect usual diet over a year-for example, because of seasonality. In addition, precise estimates require several days of data collection for nutrients with high daily variability, such as vitamin A (12). Notably, Hankin and colleagues (1) found higher correlations when they compared their FFQ with 28 days of dietary records collected over 1 year. At the very least, however, our analysis allowed for evaluation of the most commonly consumed foods and for nutrients with relatively low day-to-day variability, such as calcium.

A standard approach to developing population-specific FFQs involves analyzing multiple 24-hour recalls or records from the target population to identify important foods; grouping foods based on consumption and nutrient profile similarities; and selecting nutrient values for the food group, usually using weighted means or medians (13). Findings from this and previous work $(14,15)$ suggest that, when resources are limited, previously developed FFQs are a useful starting point for developing an FFQ targeting a slightly different population. Collecting quantitative intake data, however, remains crucial for informing decisions on appropriateness of food-list items, portion-size choices, and nutrient values.

\section{CONCLUSIONS}

These analyses identify specific strengths and weaknesses of the FFQ, provide some assurance of its adequacy for describing selected food and nutrient intake in the targeted sample, and serve as the basis for further improvements. The FFQ may be useful for examining intake of commonly consumed foods, such as meat and fish, fruits, and tofu, and selected nutrients such as folate and calcium. Better performance in ranking intake of nutrients such as total fat and vitamin A, however, will require further research and refinement. Future work will also address the FFQ's reliability and provide calibration data for correcting estimates of diet-disease associations.

The authors thank Yun Song for her work in data collection and management, Andrew Balshem and Liat Shimoni for their assistance in processing data for the analyses, and Joanne Dorgan for her input on the manuscript. This research was supported by grants IRG-92-027-09 and CRTG-01-018-01-CCE from the American Cancer Society.

\section{References}

1. Hankin J, Wilkens L, Kolonel L, Yoshizawa C. Validation of a quantitative diet history method in Hawaii. Am J Epidemiol. 1991;133:616-628.

2. Lee M, Lee F, Ladenla S, Miike R. A semiquantitative dietary history questionnaire for Chinese Americans. Ann Epidemiol. 1994;4:188-197.

3. Hernandez T. Asian Assist: A bilingual dietary assessment program for Chinese Americans. J Food Comp Anal. 2001;14:245-252.

4. US Department of Agriculture. 1994-96 Continuing Survey of Food Intakes by Individuals and related survey materials. Washington, DC: US Department of Agriculture; 1999.

5. US Department of Agriculture Agricultural Research Service. USDA Nutrient Database for Standard Reference, Release 12. 1998. Available at: http://www. nal.usda.gov/fnic/foodcomp. Accessed July 1, 2001.

6. Holden JM, Eldridge AL, Beecher GR, Buzzard IM, Bhagwat SA, Davis CS, Douglass LW, Gebhardt SE, Haytowitz DB, Schakel S. Carotenoid content of U.S. foods: An update of the database. J Food Comp Anal. 1999;12:169-196.

7. Willett W, Stampfer M. Total energy intake: Implications for epidemiologic analyses. Am J Epidemiol. 1986;124:17-27.

8. Salvini S, Hunter DJ, Sampson L, Stampfer MJ, Colditz GA, Rosner B, Willett WC. Food-based validation of a dietary questionnaire: The effects of weekto-week variation in food consumption. Int J Epidemiol. 1989;18:858-867.

9. VandenLangenberg GM, Brady WE, Nebeling LC, Block G, Forman M, Bowen PE, Stacewicz-Sapuntzakis M, Mares-Perlman JA. Influence of using different sources of carotenoid data in epidemiologic studies. J Am Diet Assoc. 1996;96:1271-1275.

10. Ritenbaugh C, Peng YM, Aickin M, Graver E, Branch M, Alberts DS. New carotenoid values for foods improve relationship of food frequency questionnaire intake estimates to plasma values. Cancer Epidemiol Biomarkers Prev. 1996;5:907-912.

11. Flegal KM, Larkin FA. Partitioning macronutrient intake estimates from a food frequency questionnaire. Am J Epidemiol. 1990;131:1046-1058.

12. Willett W. Nutritional Epidemiology. 2nd ed. New York, NY: Oxford University Press; 1998.

13. Hankin J. Lenna Frances Cooper memorial lecture: A diet history method for research, clinical, and community use. J Am Diet Assoc. 1986;86:868-875.

14. Coates R, Monteilh C. Assessments of food-frequency questionnaires in minority populations. Am J Clin Nutr. 1997;65(suppl 4):S1108-S1115.

15. Kelemen LE, Anand SS, Vuksan V, Yi Q, Teo KK, Devanesen S, Yusuf S. Development and evaluation of cultural food frequency questionnaires for South Asians, Chinese, and Europeans in North America. J Am Diet Assoc. 2003;103:1178-1184.

16. Standing Committee on the Scientific Evaluation of Dietary Reference Intakes. Dietary Reference Intakes for Vitamin A, Vitamin K, Arsenic, Boron, Chromium, Copper, Iodine, Iron, Manganese, Molybdenum, Nickel, Silicon, Vanadium, and Zinc: A Report of the Panel on Micronutrients. Washington, DC: National Academy Press; 2001. 